\title{
Correspondence
}

\section{FoxP3 mRNA Expression in Regulatory T Cells from Patients with Tuberculosis}

To the Editor:

We read with great interest the article by Guyot-Revol and colleagues (1) assessing the role of $\mathrm{T}$ regulatory cells (Tregs) in tuberculosis (TB) pathogenesis. Guyot-Revol and coworkers found that in patients with $\mathrm{TB}$, percentages of $\mathrm{CD} 4+\mathrm{CD} 25^{\text {high }}$ $\mathrm{T}$ cells and levels of FoxP3 mRNA expression in peripheral blood mononuclear cells were both significantly higher in comparison with controls. To better comprehend Tregs' mechanism of action, the authors investigated whether the increased levels of FoxP3 mRNA that they had observed were effectively caused by increased gene expression, or were simply the result of increased CD4+CD25 $5^{\text {high }}$ frequency. FoxP3 mRNA in CD4+CD25+ $\mathrm{T}$ cells was compared between patients with $\mathrm{TB}$ and control subjects. As no quantitative difference was observed, the authors suggest that the greater levels of FoxP3 mRNA are simply an effect of increases in Treg frequency rather than a result of an up-regulated gene expression.

The transcription factor FoxP3 is the most specific molecular marker for Tregs available to date, and its correct evaluation is crucial (2-4). In the analysis of Treg dynamics, an assessment of what happens in the frequency and level of FoxP3 mRNA expression at the single cell level is mandatory. The recent literature demonstrates a strong correlation between levels of CD25 expression and the frequency of FoxP3-positive cells in healthy donors (4), and suggests that to correctly evaluate FoxP3 expression in Tregs, mRNA should be quantified in CD $4+\mathrm{CD} 25^{\text {high, }}$ rather than in CD4+CD25+ T cells (5).

We are currently performing a prospective study to evaluate Tregs in patients with TB. Analysis of CD $4+\mathrm{CD} 25^{\text {high }}$ percentage on CD4 T cells at TB diagnosis showed similar levels of Tregs among patients with TB and controls (median percentage: $2.1 \%$ [IQR, 1.8-6.6] vs. 1.9\% [IQR, 1.5-2.2]). Unlike Guyot-Revol and coworkers, we evaluated FoxP3 mRNA expression by real-time polymerase chain reaction in $\mathrm{CD} 4+\mathrm{CD} 25^{\text {high }} \mathrm{T}$ cells, purified using an EPICS ALTRA Cell Sorter (Beckman-Coulter; purity > 93.6\%). A considerable increase of FoxP3 mRNA expression in patients with TB with respect to control subjects was clearly observed (median: 39.1 [IQR, 5.1-109] vs. 1.6 [IQR, 0.8-2.8]; p < 0.0062). These data implicate FoxP3 gene overexpression as a probable mechanism involving Tregs in the pathogenesis of TB, and suggest a possible role of FoxP3 gene up-regulation in the outcome of chronic infections.

Our results underscore the importance of using the correct methodology in evaluating Treg cell dynamics, and prove that an accurate evaluation of FoxP3 mRNA expression in Treg cells may lead to the identification of previously unknown mechanisms of Treg cell involvement in disease pathogenesis.

Conflict of Interest Statement: None of the authors has a financial relationship with a commercial entity that has an interest in the subject of this manuscript.

\author{
Lidia Gazzola \\ Camilla Tincati \\ ANDREA GoRI \\ "San Paolo" Hospital \\ University of Milan \\ Milan, Italy
}

\author{
Marina Saresella \\ IVANA MaRventano \\ "Don C. Gnocchi” Foundation, IRCCS \\ Milan, Italy \\ FABIO ZANINI \\ "Luigi Sacco" Hospital \\ University of Milan \\ Milan, Italy
}

\section{References}

1. Guyot-Revol V, Innes JA, Hackforth S, Hinks T, Lalvani A. Regulatory T cells are expanded in blood and disease sites in tuberculosis patients. Am J Respir Crit Care Med 2006;173:803-810.

2. Viguier M, Lemaitre F, Verola O, Cho M-S, Gorochov G, Dubertret L, Bachelez H, Kourilsky P, Ferradini L. FoxP3 expressing CD4 ${ }^{+} \mathrm{CD} 25^{\text {high }}$ regulatory $\mathrm{T}$ cells are overrepresented in human metastatic melanoma lymph nodes and inhibit the function of infiltrating T cells. J Immunol 2004;173:1444-1453.

3. Fontenot JD, Gavin MA, Rudensky AY. FoxP3 programs the development and function of $\mathrm{CD}^{+} \mathrm{CD} 25^{+}$regulatory $\mathrm{T}$ cells. Nat Immunol 2003;4:330-336.

4. Fontenot JD, Rudensky AY. A well adapted regulatory contrivance: regulatory $\mathrm{T}$ cells development and the forkhead family transcription factor FoxP3. Nat Immunol 2005;6:331-337.

5. Rocandor G, Brown PJ, Maestre L, Hue S, Martinez-Torrecuadrada JL, Ling K-L, Pratap S, Toms C, Fox BC, Cerundolo V, et al. Analysis of FoxP3 protein expression in human CD4+CD25+ regulatory T cells at the single-cell level. Eur J Immunol 2005;35:1681-1691.

From the Authors:

We thank Gazzola and colleagues for their interest in our recent article, the first to describe a role for regulatory $\mathrm{T}$ cells (Tregs) in tuberculosis (1). Our main finding was an increased percentage of CD4+CD25 high $\mathrm{T}$ cells in the CD4+ T-cell fraction of peripheral blood mononuclear cells (PBMCs), and increased FoxP3 mRNA expression in PBMCs in patients with tuberculosis compared with healthy control subjects. In contrast, Gazzola and coworkers' interim results from their ongoing study (as mentioned in their letter) show no increase in CD4+CD25 high $\mathrm{T}$ cells in patients with tuberculosis compared with healthy control subjects, and they seem not to have measured FoxP3 expression in PBMCs. The median proportion of CD4+CD25 5 high $\mathrm{T}$ cells in their healthy controls $(1.9 \%)$ was not dissimilar to ours $(1.17 \%)$, suggesting that our gating was comparable.

When we compared FoxP3 mRNA expression in CD4+CD25+ $\mathrm{T}$ cells in patients and controls, we found no significant difference, suggesting that the increased FoxP3 expression in tuberculosis reflects increased frequencies of Tregs rather than increased expression of FoxP3 per cell. Gazzola and coworkers compared FoxP3 expression in CD4 + CD25 $5^{\text {high }} \mathrm{T}$ cells and found a 24-fold increase in patients with tuberculosis. In general, CD4+CD25+ $\mathrm{T}$ cells constitute about $5-10 \%$ of $\mathrm{CD} 4+\mathrm{T}$ cells, whereas CD4+CD25 high $\mathrm{T}$ cells constitute about $1-2 \%$. Therefore, if $\mathrm{CD} 4+\mathrm{CD} 25^{\text {high }} \mathrm{T}$ cells in our patients with tuberculosis were expressing 24 times more FoxP3 than in our controls, we should have observed an approximate four- or fivefold increase in FoxP3 expression in the CD4+CD25+ T-cell fraction, $20 \%$ of which was composed of CD $4+\mathrm{CD} 25^{\text {high }} \mathrm{T}$ cells. The fact that we did not see such a difference is at variance with Gazzola and coworkers' observation. Thus, two of Gazzola and coworkers' findings are in contrast to our own for unclear reasons. However, we are not 